\title{
Application of Graduate Profile with Empowering Leadership Training at University
}

\author{
Natalia Hartono \\ Faculty of Science and Technology \\ University of Pelita Harapan \\ Tangerang, Indonesia \\ natalia.hartono@uph.edu
}

\author{
Andry M. Panjaitan \\ Faculty of Science and Technology \\ University of Pelita Harapan \\ Tangerang, Indonesia \\ andry.panjaitan@uph.edu
}

\author{
Siagian Sidarta \\ Faculty of Science and Technology \\ University of Pelita Harapan \\ Tangerang, Indonesia \\ siagian_s@ @otmail.com
}

\begin{abstract}
-being a leader equipped with a vision of transformation is proposed as graduate profile in a university. The disciplinary method needs to be conducted as part of the training to fulfill the graduate profile. The training method has changed but there was no evaluation conducted to analyze the new method. The purpose of this research was to apply graduate profile with empowering leadership training. The subject of this research was Mentor Intermediate Training Extra (MITx). The training was designed according to the theoretical model. A twopart questionnaire was used to collect data after the training. The data then processed using Structural Equation Modeling (SEM) with the help of IBM SPSS Statistics version 22 and IBM SPSS Amos 22. The results showed that empowering leadership has a positive impact on psychological empowerment and psychological empowerment has a positive impact on training-level learning. The empowering leadership methods encourage $86.4 \%$ of the trainee to follow the empowering rules and learn the empowering rules value, $81.4 \%$ of the trainee gave a positive opinion for empowering leadership method, $86 \%$ of the trainee thinks it is better to apply this method for other training.
\end{abstract}

Keywords-training; disciplinary method; empowering leadership; psychological empowerment; Structural Equation Modeling

\section{INTRODUCTION}

One of the University of Pelita Harapan (UPH) graduate profile is a leader equipped with a vision of transformation [1]. UPH has some leadership training and one of the training is Mentor Intermediate Training Extra (MITx). At UPH, one of the important parts in training was the disciplinary method. UPH had been using semi-military disciplinary methods, but it has been changed to non-semi-military method since 2015 . Nevertheless, there has never been an evaluation of the disciplinary method. Other than that, it has never been confirmed the training conducted is based on UPH graduate profile.
Leadership is a relational and ethical process of people together attempting to accomplish positive change and leadership can be learned [2]. Leadership skills learned and applied in the training condition is called training-level learning [3]. This research use theory about empowering leadership because it fits the training condition at UPH. Empowering leadership is defined as "the process of implementing conditions that enable sharing power with an employee by delineating the significance of the employee's job, providing greater decision-making autonomy, expressing confidence in the employee's capabilities, and removing hindrances to performance" [4].

There was a need to conduct leadership training dan evaluation of the training at UPH that based on graduate profile with the non-semi-military method. This research proposes to conduct the training with the non-semi-military method, that is empowering leadership method, using the model from Zhang and Bartol with some adjustments. Their research shows that empowering leadership positively affected psychological empowerment and empowerment role identity moderated the link between empowering leadership and psychological empowerment [4]. Thus, the purpose of this research was to apply graduate profile with empowering leadership training at the University of Pelita Harapan.

\section{METHODS}

The first step in this research was designing MITx using empowering leadership theory based on the research model. After the training, the trainee was asked to fill the two-part questionnaire. The first part to measure the model and analyze whether empowering leadership as a disciplinary method affect more positively to trainee training-level learning than the semi-military method in an effort to achieve UPH graduate profile. The second part to collect opinion about the training from the trainee for evaluation. The training was carried out 
for two days on $18^{\text {th }}$ and $19^{\text {th }}$ November 2016 at UPH. The model in this research presented in Fig 1.

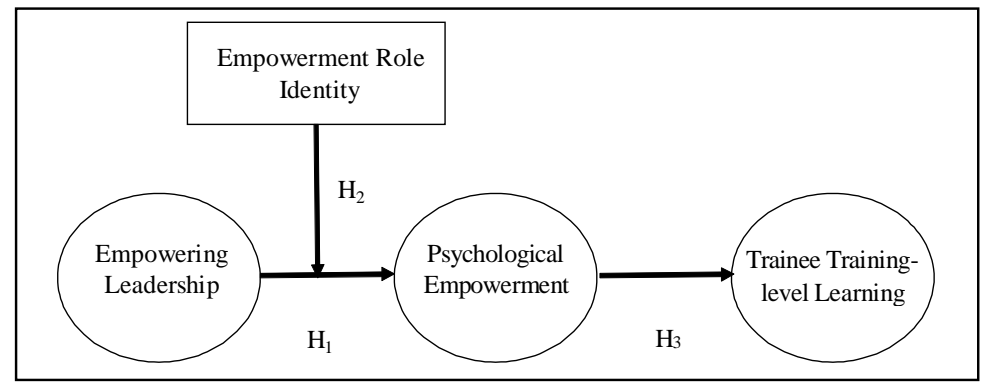

Fig. 1. Research Model

There were three hypotheses in this research:

1. Hypotheses 1: Empowering leadership is positively related to psychological empowerment.

2. Hypotheses 2: Empowering role identity to strengthen the relationship of empowering leadership and psychological empowerment.

3. Hypotheses 3: Psychological empowerment is positively related to training-level learning.

This research designed the first questionnaire based on theories that were taken from Zhang and Bartol research with some adjustments. The adjustment was carefully thought and discussed between the researchers. The questionnaire used a six-point Likert-type scale ranging from "strongly disagree" to "strongly agree". Dimension for Empowering Leadership, Empowering Identity, Psychological Empowerment was taken from Zhang and Bartol research [4]. Dimension for Traininglevel training was taken from the Chief Mentor Profile University of Pelita Harapan. The research dimension presented in Table I.

\section{TABLE I. RESEARCH DIMENSION}

\begin{tabular}{|l|l|}
\hline \multicolumn{1}{|c|}{ Vari abl e } & \multicolumn{1}{|c|}{ Di m e n si on } \\
\hline \multirow{4}{*}{ Em po wering Leadership } & Ex press Con fidence \\
\cline { 2 - 2 } & P ro vide Aut onom y \\
\cline { 2 - 2 } & P ro mo t e P art icipat ion \\
\cline { 2 - 2 } Em po wering Role Ident it y & En han ce Meaning \\
\cline { 2 - 2 } & W illingness t o learn \\
\hline \multirow{4}{*}{ P sych olo gical Em powerm en $\mathrm{t}$ illingness t o at t end t raining } \\
\cline { 2 - 2 } & Self-det erm inat ion \\
\cline { 2 - 2 } & Meaning \\
\cline { 2 - 2 } T rain ing-lev el learnin $g$ & Co mp et ence \\
\hline & Init iat ive \\
\cline { 2 - 2 } & Creat ive \\
\cline { 2 - 2 } & Discipline \\
\cline { 2 - 2 } & Humilit y \\
\cline { 2 - 2 } & Servant Leader \\
\hline
\end{tabular}

The validity and reliability of this research were tested using the help of IBM SPSS software version 22. The next step is to test the model using Structural Equation Modelling (SEM) with the help of IBM SPSS Amos 22.
The second questionnaire was designed to collect opinion from the trainee after the MITx conducted for evaluation of the training method. The descriptive statistic used to process the second questionnaire.

\section{ANALYSIS}

This research uses face validity to make sure the words used in the questionnaire are understandable and unambiguous for the two-part questionnaire. After the training conducted, the questionnaire was filled by the trainees. There were 83 trainees, but only 59 usable survey data that can be used for the next process.

The construct validity performed for first part of the questionnaire using Pearson correlation. The results showed that all item valid because the $r$ was bigger than the $r$ obtained from the table (0.257) with significance 0.05 .

Then this research test the reliability of the first part of the questionnaire used Cronbach Alpha. The description of the measurement described below with the Cronbach's Alpha value.

- $\quad$ Empowering Leadership There are four dimensions used to measure empowering leadership: (1) Express confidence ( $\alpha$ 's $=0.779,0.673$, and 0.786 for each question), (2) Promote participation $(\alpha$ 's $=0.662)$, (3) Provide autonomy ( $\alpha$ 's $=0.450)$, (4) Enhance meaning ( $\alpha$ 's $=$ $0.674,0.558$, and 0.657 for each question). Provide autonomy did not met the requirement in this study and therefore was deleted.

- Empowering Role Identity

Empowering role identity measurements are used based on the willingness of the trainee to learn ( $\alpha$ 's $=$ 0.476 ) and willingness to attend training ( $\alpha$ 's $=$ 0.476). These results show that empowering role identity must be deleted.

- Psychological Empowerment

There are four dimensions used to measure psychological empowerment, which are: (1) Selfdetermination ( $\alpha$ 's $=0.420$ and 0.366), (2) Impact $(\alpha$ 's $=0.491$ and 0.639$),(3)$ Meaning ( $\alpha$ 's $=0.510$ 
and 0.551), (4) Competence ( $\alpha$ 's $=0.626$ and 0.567). Although some of the Cronbach's Alpha value is below 0.6, the overall Cronbach's Alpha value is 0.808 and will decrease if any of the question used is removed. Therefore, all of the measurements in the psychological empowerment were used.

- $\quad$ Training-level Learning

Training-level learning measurements are used based on the Chief Mentor Profile of Mentoring UPH. There are five dimensions used to measure the training-level learning, which is: (1) Initiative ( $\alpha$ 's $=$ $0.487)$, (2) Creative ( $\alpha$ 's $=0.382)$, (3) Discipline ( $\alpha$ 's $=0.643$ ), (4) Humility ( $\alpha$ 's $=0.665)$, (5) Servant Leader $(\alpha$ 's $=0.480)$. The creative measurement is removed to increase the overall Cronbach's Alpha value from 0.750 to 0.760 .

The second part of the questionnaire was designed to collect the opinion of the trainees. This opinion section was excluded from SEM analysis. It was processed using descriptive statistics to collect and evaluate the MITx.

\section{RESULTS AND DISCUSSION}

Structural Equation Modelling (SEM) was used to examine the hypothesized model. This research use IBM SPSS version 22. The final results showed that the model with deletion of variable empowering role identity and dimension provide autonomy and creative, has an acceptable fit to the model $(\mathrm{p}=$ $0 ; \mathrm{x}^{2} / \mathrm{df}=2.425 ; \mathrm{GFI}=0.782 ; \mathrm{AGFI}=0.657 ; \mathrm{ECVI}=2.583 ;$ $\mathrm{AIC}=149.842 ; \mathrm{CAIC}=223.703 ; \mathrm{CFI}=0.88 ; \mathrm{RFI}=0.759 ;$ RMR $=0.021 ;$ SRMR $=0.111$ ). Table II showed all the fit index used and Fig. 2. showed the Structural Equation Model with its standardized value.

TABLE II. MODEL FIT INDEX

\begin{tabular}{|c|c|c|c|c|}
\hline Criteria & Cut-Off & Value & $\begin{array}{c}\text { Saturated } \\
\text { Model }\end{array}$ & $\begin{array}{c}\text { Independence } \\
\text { Model }\end{array}$ \\
\hline Chi-Square & $\mathrm{P}>0,05$ & 0 & - & 0 \\
\hline GFI & $>0,9$ & 0.782 & 1 & 0.297 \\
\hline AGFI & $>0,9$ & 0.657 & - & 0.156 \\
\hline ECVI & $\begin{array}{c}\text { Model < Saturated } \\
\& \text { Independence }\end{array}$ & 2.583 & 2.276 & 9.932 \\
\hline AIC & $\begin{array}{c}\text { Model < Saturated } \\
\& \text { Independence }\end{array}$ & 149.84 & 132 & 576.066 \\
\hline CAIC & $\begin{array}{c}\text { Model < Saturated } \\
\& \text { Independence }\end{array}$ & 223.7 & 335.117 & 609.919 \\
\hline CFI & $>0,9$ & 0.88 & 1 & 0 \\
\hline RFI & $0-1$ & 0.759 & & 0 \\
\hline RMR & $<0,08$ & 0.021 & 0 & 0.083 \\
\hline SRMR & $\leq 0,08$ & 0.111 & - & - \\
\hline
\end{tabular}

The SEM results supported Hypotheses 1 and 3. Hypotheses 1 states that empowering leadership is positively related to psychological empowerment. The model result support that hypotheses with $=0.64$. Hypotheses 3 states that psychological empowerment is positively related to traininglevel learning. The model result also supports that hypotheses with $=0.57$. Hypotheses 2 were not conducted since the measurement variable has been removed from the model.

Results from opinion questions to gather opinion from the trainee about empowering method compare to the semimilitary method. The study showed that $85.4 \%$ (35 out of 41 trainees) of the trainees who have been experienced semimilitary discipline method were encouraged to follow the empowering rules and learned about the empowering rules value. A similar thing also happens to the trainees whom never experienced semi-military discipline method, with the percentage of $88.9 \%$ (16 out of 18 trainees).

Total results from all trainee who attend MITx, 86.4\% (51 out of 59 trainees) were encouraged to follow the empowering rules and learn about the empowering rules value, $6.8 \%$ (4 out of 59 trainees) were encouraged to follow the empowering rules but did not learn the empowering rules value, 5.1\% (3 out of 59 trainees) were not encouraged to follow the empowering rules but still learn the empowering rules value, and $1.7 \%$ ( 1 out of 59 trainees) were not encouraged to follow the empowering rules or learn about the empowering rules value. This shows that the empowering leadership methods did encourage most of the trainee to follow the empowering rules and learn the empowering rules value.

Trainee in MITx was also asked to give their opinion on empowering leadership method. The opinion answers were categorized into two categories, positive and negative. The result showed that $82.5 \%$ (32 out of 41 trainees) of the trainees whom experienced semi-military discipline give a positive opinion on empowering leadership. A similar thing also happens to the trainees whom never experienced semi-military discipline method before, with the percentage of $77.8 \%$ (14 out of 18 trainees). The sum of all trainee from MITx, $81.4 \%$ (48 out of 59 trainees) gave a positive opinion, $11.9 \%$ (7 out of 59 trainees) gave a negative opinion, and $6.8 \%$ (4 out of 59 trainees) gave no opinion on this. The result shows that $86 \%$ (51 out of 59 trainees) think it is better to apply this method for other leadership training and $14 \%$ (8 out of 59 trainees) thinks otherwise.

This research support Zhang and Bartol model that empowering leadership relates positively to psychological empowerment and psychological empowerment is positively related to training-level training. This shows that this method can be used as a disciplinary method and it will give positive impact to the trainee training-level learning. However, it is not known whether empowering leadership and psychological empowerment relationship can be strengthened with the appropriate empowering role identity. 


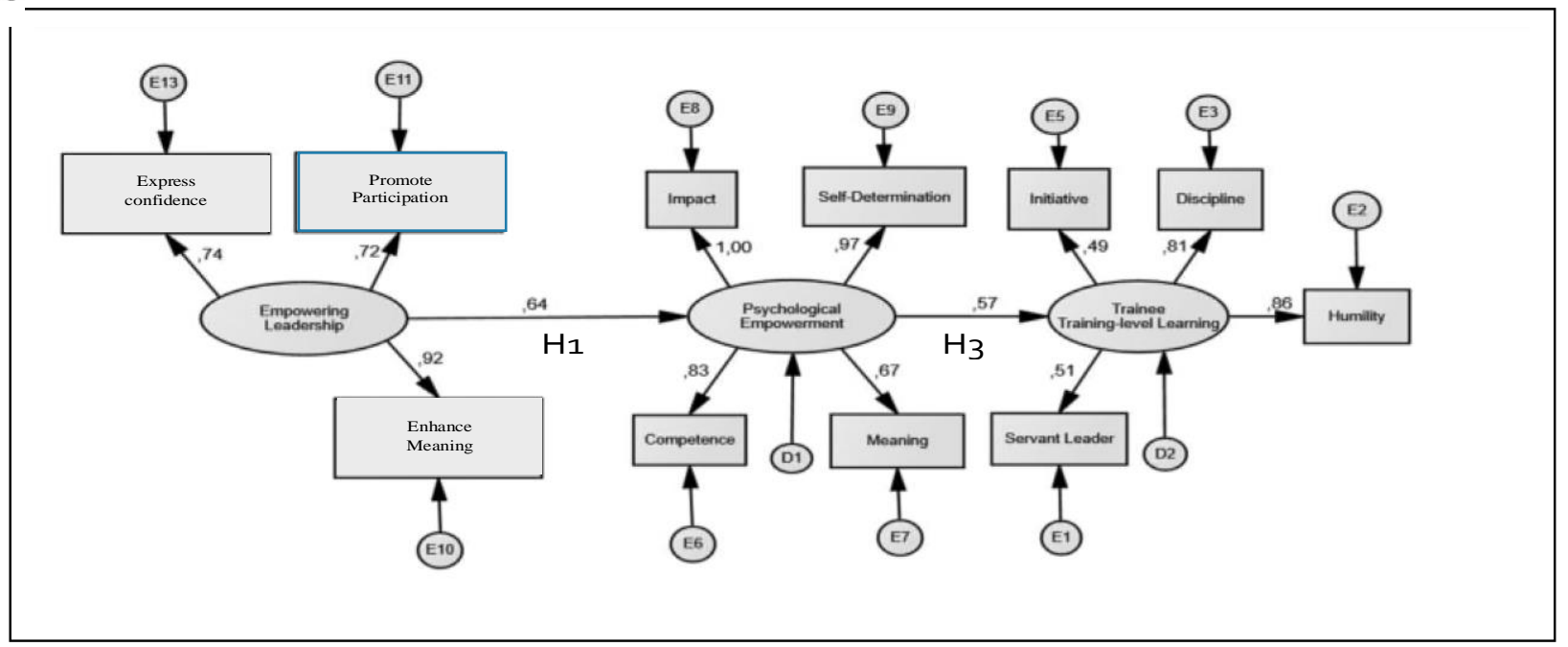

Fig. 2. SEM Results

The second part of the questionnaire gather opinion and the result shows that the trainee prefers having the empowerment leadership method rather than the semi-military method. The trainee prefers a disciplinary method that was not forcing the trainee, reflective, encourage the trainee to have the desire to grow, make trainee feel trusted, there was an explanation of the value of the rules, and make the trainee feel responsible. Those reasons were aligned with the adult education, where force may cause the trainee to shut down the new idea and where the trainee needs to know why they must do something. Those kinds of the disciplinary method can be provided using the empowering leadership.

Although the empowering leadership proves to relate positively to psychological empowerment and affect the training-level learning [5] [6], not all the trainee agree that this method should be applied in other training. Short interviews are conducted to know more about this and the result shows that it may not be possible to apply this method other than MITx due to the trainee who participate in MITx have been filtered through other training, at least they have to join Training Mentor (training given to someone before he become a Mentor in Mentoring UPH). Other than that, the committee in MITx is known to be a reliable learning resource to the trainee because they consist of the alumni and the Head Mentor of the Mentoring UPH. Filtered participants may not always be a factor of successful method or training because each training has its own target and trainee population. Leadership training conducted for the new students will have a different target of training with MITx who targeted student who is a Mentor and have gone through all the requirement to be a mentor. Other than that, the training conducted by the students can also have a reliable learning resource from the committee. This is because the training conducted will have their committee fulfill some requirement by the organization that conducts the training before they can become part of the committee. Although that two-issue can be solved, it still should be noted if this method will be used in other training. Other than the disciplinary methods, the study also shows that MITx training conducted are aligned with UPH Graduate Profile. Mentoring UPH has a standard for their training built on the UPH Graduate Profiles. It was shown by how the training uses the UPH Graduate Profile as the foundation of the lecture, simulation, talk show, and team building games.

\section{CONCLUSION}

In conclusion, this research results that the training was designed to aligned with UPH graduate profile and the training used empowering leadership as a disciplinary method that affects positively to the trainee training-level learning. This research support Zhang and Bartol model that empowering leadership relates positively to psychological empowerment and psychological empowerment is positively related to training-level training.

Some suggestions for further research were study about empowering role identity need to be conducted to know its effect as a moderator variable. Next, study about empowering leadership effect on transfer of training should be conducted to examine the effect of empowering leadership outside of training.

\section{ACKNOWLEDGEMENT}

I would like to thank Universitas Muhammadiyah Sidoarjo for giving me an opportunity to publish my paper.

\section{REFERENCES}

[1] U. of P. Harapan, "Vision and Mission." [Online]. Available: https://www.uph.edu/about-uph/uph-identity/vision-and-mission .html . [Accessed: 15-Oct-2016].

[2] K. S. L. N. M. TR, Exploring Leadership: For College Students Who Want To Make a Difference, 3rd ed. San Fransisco: JosseyBass, 2013. 
[3] S. PE, Industrial And Organizational Psychology: Research And Practice, 6th ed. Singapore: John Wiley \& Sons, 2012.

[4] B. K. Zhang XM, "Linking Empowering Leadership And Employee Creativity: The Influence Of Psychological Empowerment, Intrinsic Motivation, And Creative Process Engagement," Acad. Manag. J., vol. 53, no. 1, pp. 107-128, 2010.

[5] R. Z., Kuo \& G. G., Lee. "Knowledge management system adoption: exploring the effects of empowering leadership, task-technology fit and compatibility". Behaviour \& Information Technology, 30(1), 113-129, 2011.

[6] G. L., Filan. "The need for leadership training: The evolution of the chair academy. New Directions for Community Colleges, 1999(105), 47-55, 1999. 